This is a pre-publication version of the following article:

Liddon, L., Kingerlee, R., \& Barry, J. A. (2017). Gender differences in preferences for psychological treatment, coping strategies, and triggers to help-seeking. British Journal of Clinical Psychology. 9 JUL 2017, DOI: 10.1111/bjc.12147

\title{
Gender differences in preferences for psychological treatment, coping strategies, and triggers to help-seeking
}

\author{
Louise Liddon ${ }^{1}$, Roger Kingerlee ${ }^{2}$ and John A. Barry ${ }^{3}$. \\ ${ }^{1}$ Northumbria University, Newcastle, UK \\ ${ }^{2}$ Norfolk and Suffolk NHS Foundation Trust, Norwich, UK \\ ${ }^{3}$ Clinical, Educational and Health Psychology, University College London, UK
}

Objective. There is some evidence that men and women deal with stress in different ways; for example, a meta-analysis found that women prefer to focus on emotions as a coping strategy more than men do. However, sex differences in preferences for therapy is a subject little explored.

Design. A cross-sectional online survey.

Method. Participants (115 men and 232 women) were recruited via relevant websites and social media. The survey described therapies and asked participants how much they liked each. Their coping strategies and help-seeking behaviour were assessed too.

Results. Survey data were analysed using multiple linear regression. After familywise adjustment of the alpha for multiple testing to $p<.0125$, and controlling for other relevant variables, men liked support groups more than women $\operatorname{did}(\beta=-.163, p<.010)$, used sex or pornography to cope with stress more than women $\operatorname{did}(\operatorname{Exp}(\mathrm{B})=.280, p<.0002)$, and thought that there is a lack of male-friendly options more than women $\operatorname{did}(\operatorname{Exp}(\mathrm{B})=.264, p<.002)$. The majority of participants expressed no preference for the sex of their therapist, but of those who did, men were only slightly more likely to prefer a female therapist whereas women were much more likely to prefer females $(p<.0004)$. Even after familywise adjustment, there were still more significant findings than would be expected by chance $(p<.001$, two-tailed).

Conclusions. Although there are many similarities in the preferences of men and women regarding therapy, our findings support the hypothesis that men and women show statistically significant differences of relevance to clinical psychologists. 


\section{Practitioner points}

- Men are less inclined than women to seek help for psychological issues

- This study demonstrates that men and women show significant differences in some aspects of therapy, coping behaviour, and help-seeking

- It is possible that men would be more inclined to seek help if therapies catered more for men's preferences

- Practitioners can learn to improve the success of their practice by taking the gender of clients into account

Despite the fact that three to four times more men than women commit suicide (19 vs. 5.1 per 100,000; ONS, 2015), men do not seek psychological help as much as women do (Addis \& Mahalik, 2003; Kung, Pearson, \& Liu, 2003). Some authors suggest that this might be because the types of treatment on offer are less appealing to men than women because, for example, many psychological interventions are more emotion-focused than solution-focused, thus preferred by women rather than men (Kingerlee, Precious, Sullivan, \& Barry, 2014; Wilkins, 2010). It may be that men benefit as much as women from emotional disclosure, but men may be put off seeking help because of reluctance to engage in interventions in which the focus is on emotional disclosure (Holloway, Seager, \& Barry, in review).

Many studies do not report gender differences in the outcome of psychological treatment (Parker, Blanch, \& Crawford, 2011). However, in the rare examples of where gender is taken into account, men and women may respond differentially to a range of treatments (e.g., Green, Lynn, \& Montgomery, 2008; Health and Social Care Information Centre, 2014; Wright \& McLeod, 2016).

Some research has identified specific gender differences in client needs. For example, Peterson et al. (2012, p.3) suggest that 'It is essential that infertility counselors be aware of how men and women experience infertility differently'. They describe, for example, the 'common dynamic' where a man attempts to help his female partner using problem- solving strategies to protect her from her emotional pain, leaving the woman feeling emotionally invalidated.

In interviews with a range of experienced psychological therapists, it was found that most describe gender differences in various aspects of therapy (Lemkey, Brown, \& Barry, 2015; Russ, Ellam-Dyson, Seager, \& Barry, 2015). These differences can be summarized as 'men seek a quick solution, whereas women want to talk about their feelings (Holloway et al., in review)'.

Although men and women may equally benefit from emotional sharing, they might have different starting points ('ports of entry') in therapy (Holloway et al., in review). Golden (2013) suggests that grieving men sometimes display a grieving 'action' (e.g., writing a book or song about a recently departed loved one) rather than crying and 
talking about feelings. In such cases, rather than encouraging emotional sharing and direct eye contact, therapy should move indirectly to the subject of feelings by talking first about the grieving action.

Men and women may have different preferences for the gender of their therapist. For example, a study of psychotherapy clients found that most female clients preferred a female therapist and most male clients expressed no preference regarding the gender of their therapist, but of the males who did voice preferences, most preferred a female therapist (Pikus \& Heavey, 1996).

There is evidence of gender differences in coping with stress. A survey of over 1,000 people found that when severely depressed, women were more likely than men (67\% compared to 55\%) to talk to someone (CALM (The Campaign Against Living Miserably), 2016). Taylor et al. (2000) suggested a sex difference in the behavioural response to stress; although both men and women have a physiological experience of fight or flight, it is more typical of women to have a behavioural experience of 'tend and befriend', for example, engage in nurturing activities designed to protect the self and offspring, and maintenance of social networks. This sex difference is likely to be related to sex differences in oxytocin and oestrogen, and in parenting requirements. A metaanalysis (Tamres, Janicki, \& Helgeson, 2002) found that women were more likely than men to use coping strategies that were emotion-focused (that alter a response to a stressor) as opposed to problem-focused (which are aimed at altering the stressor). For example, it was found that women tend to cope with stress by talking about their feelings more than men do.

There is evidence that men and women differ in regard to the things that cause them to seek psychological help. For example, men were more likely to open up about personal issues when it was impacting their work (Russ et al., 2015) or when prompted by a female family member or partner (Lemkey et al., 2015; Norcross, Ramirez, \& Palinkas, 1996). Men and women also show differences in what they perceive as barriers to help-seeking. For example, stigma (Clement et al., 2015) and embarrassment (CALM (The Campaign Against Living Miserably), 2016) are more of a deterrent for men than women. There is also evidence of a cultural impact on help-seeking (Opinium Research, 2016).

The present study sought to discover the views of the general public on their preferences for therapy and related issues. We hypothesized that men and women would show differences in: (1) their preferences for types of psychological intervention, (2) preferences for other aspects of therapy, (3) their coping strategies, and (4) the triggers to seeking help.

\section{Method}




\section{Participants}

Participants were recruited via invitations on various websites and social media, such as the Men's Health Forum and Psychology on The Net. Participants were excluded if they were under 18 years old, did not give key information (gender or mental health status), or did not complete the consent form. Participants indicated their informed consent to take part in the study by ticking a box in a consent form following the information sheet. Ethical approval was granted by the Research Ethics Committee.

\section{Procedure}

An invitation to participate in the study was posted on participating websites. Participants were briefed that the survey was about what makes people decide to seek help and what kind of help they decide to choose, as well as whether men and women make these decisions differently. The survey took about 20 min to complete.

\section{Design}

This study was a cross-sectional online survey analysed using either multiple linear regression or logistic regression. Dependent variables were the degree of liking for various aspects of psychological therapy, and the main predictor was the sex of the participant. Other potentially relevant variables (age, educational level, etc.) were entered into the statistical models. Data were analysed using SPSS statistical software, Version 22.

\section{Measures}

\section{Dependent variables}

The primary outcome variables were the degree of liking for various aspects of therapy. This was operationalized in four ways: (1) In the first section, participants were asked 'If you had a mental health problem, what kind of treatment would you prefer?' The list of treatment options is shown in Table 2. Response options were on a 6-point Likert scale from 1 = strongly dislike to $6=$ strongly like. (2) In the second section, participants were asked 'If you had a mental health problem, how would you prefer it to be treated?' with a list of options (see Table 3). Response options were on a 6-point Likert scale from $1=$ strongly dislike to $6=$ strongly like. (3) In the third section, participants were asked 'If you had a mental health problem, please tell us about any other ways that you might seek to deal with it', with the choice to select any number of options from a list (see Table 4).

(4) In the final section, participants were asked 'When you have a problem (worry, depression, etc.), is there any particular thing that makes you actually go to seek help?' answered using free text. The free-text responses were later subject to content analysis, and the categories of responses derived were used as outcome variables.

\section{Predictor variables}


There were 10 predictors in the final model (Gender, Age, Ethnicity, from a Westernized country, Educational status, Occupational status, Marital status, Income, Relied on by others, and Whether have had therapy before). There were originally 11, but one ('History of mental health issues') was removed from analysis because it was collinear with 'Whether have had therapy before' $\left(r=.699, n=318, p=2.5910^{48}\right)$.

Gender, coded: Male $=1$; Female $=2$; Other $=3$. There were too few 'Other' participants for sufficient statistical power, so 'Other' was not used in analyses. Age was measured in years. Ethnicity: Caucasian $=1$; All other $=2$. Westernized countries were North America, Europe, Australia, and New Zealand, and coded: $1=$ Western culture; 2 $=$ Other culture. Education status: $1=$ Lowest educational level; $8=$ Highest. Occupational status: $1=$ Full time; $2=$ Part time; $3=$ Student, unemployed, or retired. Marital Status: $1=$ Single; $2=$ Divorced or widowed; $3=$ Married, cohabiting or civil partnership. Income: $1=$ Lowest income; $3=$ Highest income. Relied on by others was operationalized as the response to the statement: 'If I became unwell, either mentally or physically, this would create difficulties for people who rely on me'. Response options were on a 6-point Likert scale from $1=$ strongly agree that is relied on by others; $6=$ strongly disagree. The purpose of this question was to assess the degree to which feeling responsible for the welfare of others would impact ways of dealing with stress (based on Brook et al., 1992). Mental health was assessed by the self-report of 'yes' or 'no' to the question: 'Have you ever been treated by a mental health professional (counsellor, psychologist, etc.) for a mental health problem?' Therapy $=(1=$ 'has previously had therapy'; 2 = 'never had therapy').

To assess mental well-being, respondents completed the Positive Mindset Index (PMI) (Barry, Folkard, \& Ayliffe, 2014). This scale consists of six items (happiness, confidence, being in control, emotional stability, motivation, and optimism) on a 5-point scale (e.g., 'very happy' to 'very unhappy') with a neutral mid-point. This scale shows good internal reliability (Cronbach's a $=.926$ ) and correlates well with the psychological subscale of the SF-12. PMI was not used as a predictor variable.

\section{Data analysis}

Missing data were deleted pairwise, so that where a participant gave some information but had not given responses to all items, data for the responses they gave could be included in the analysis. Means and SDs and parametric tests were used where relevant assumptions were met. Where parametric assumptions were not met, nonparametric tests were used. In the main tests in this study (Tables 2-5), the predictors of aspects of therapy were identified using the enter method of regression, either multiple linear regression (for continuous outcomes) or logistic regression (for binary outcomes). To adjust for multiple testing, a familywise correction to the error rate was made (Hochberg $\&$ Tamhane, 1987); four domains were tested (therapies, aspects of therapy, coping, and 
help-seeking); thus, the significance threshold became $p<.0125$ (.05/4). All statistical tests were two-tailed. All statistical analyses were carried out using SPSS statistical software for Windows, Version 22 (IBM Corp, Armonk, NY, USA).

According to Tabachnick and Fidell (2001), the sample size required for a multiple linear regression is $50+8 * \mathrm{~m}$; thus with 10 predictors, the sample size required to sufficiently power data analysis was 130 . According to Peduzzi, Concato, Kemper, Holford, and Feinstein (1996), the sample size required for logistic regression is 10 cases (from the smaller group, if $\mathrm{N}$ is unequal) per predictor. In this study, the smaller $\mathrm{N}$ was 115 men; thus with 10 predictors, the sample size required to sufficiently power the analyses was 100 . Therefore, the statistical analyses were sufficiently powered.

\section{Results}

Table 1 shows that the male and female participants were similar in: age, whether they originated from a Western country, Occupational status, Marital status, Whether relied on by others, History of mental health problems, and whether they Had therapy before. There were significant differences in ethnicity, with more non-Caucasian men. There were more women with A-levels (18\% women; $3 \%$ men) and more men with MSc degrees ( $31 \%$ men and $10 \%$ women) $\left.\chi^{2}=47.991, p<.00001\right)$ (not shown in Table1). More men were in a higher income bracket than women $\left(25 \%\right.$ men and $15 \%$ women; $\chi^{2}=$ $11.177, p<.01)$. Also, men had a significantly higher Positive Mindset Index (PMI) score than women, within the male and female normal ranges. 
Table 1. Demographic characteristics of the respondents. Values are shown as mean (SD), or frequency (percentage) as appropriate

\begin{tabular}{|c|c|c|c|c|}
\hline & & $\begin{array}{c}\text { Men } \\
(\mathrm{N}=115)\end{array}$ & $\begin{array}{l}\text { Women } \\
(\mathrm{N}=232)\end{array}$ & Test statistic \\
\hline Age, mean (SD) & & $\begin{array}{c}38.13 \\
(15.02)\end{array}$ & $\begin{array}{l}35.11 \\
(13.67)\end{array}$ & $t=1.872$ \\
\hline Ethnicity & $\begin{array}{l}\text { White } \\
\text { Other }\end{array}$ & $\begin{array}{l}73(63 \%) \\
42(37 \%)\end{array}$ & $\begin{array}{l}180(78 \%) \\
52(22 \%)\end{array}$ & $\chi^{2}=7.748^{* *}$ \\
\hline Western Culture & Yes & $97(84 \%)$ & $211(91 \%)$ & $\chi^{2}=3.358$ \\
\hline $\begin{array}{l}\text { History of mental health } \\
\text { problems }\end{array}$ & Yes & $58(50 \%)$ & $128(55 \%)$ & $\chi^{2}=0.694$ \\
\hline Had therapy before? & Yes & $54(50 \%)$ & $105(50 \%)$ & $\chi^{2}=0.000$ \\
\hline Positive Mindset Index & & $3.39(0.65)$ & $3.12(0.90)$ & $t=2.965^{* *}$ \\
\hline
\end{tabular}

\section{Preferences for therapy}

Table 2 shows the predictors of degree of liking for a therapy. The sex of the participant predicted 25\% (two of eight) of the therapies offered. 
Table 2. Mean (SD) sex difference in likability rating for therapies. For each criterion variable, the predictor variables in the models (in multiple linear regression using the enter method) were Age, Ethnicity, from a Westernized country, Educational status, Occupational status, Marital status, Income, Relied on by others, and Whether have had therapy before.

\begin{tabular}{|c|c|c|c|c|c|c|c|}
\hline Liking for therapy & $\begin{array}{c}\text { Men } \\
(\mathrm{N}=115)\end{array}$ & $\begin{array}{l}\text { Women } \\
(\mathrm{N}=232)\end{array}$ & Predictor & $\beta$ & $t$ & $p$ & Liked most by... \\
\hline CBT & $4.54(1.39)$ & $4.59(1.38)$ & Occupation & -.153 & -2.365 & $.019 *$ & Full-time \\
\hline \multirow[t]{2}{*}{ Psychotherapy } & $4.14(1.39)$ & $4.46(1.39)$ & Sex & .125 & 2.134 & $.034 *$ & Female \\
\hline & & & Marital status & .172 & 2.546 & $.011^{*}$ & Married \\
\hline \multirow[t]{3}{*}{ Life coaching } & $4.11(1.43)$ & $3.94(1.36)$ & Therapy & .122 & 2.147 & $.033 *$ & No previous \\
\hline & & & Occupation & -.142 & -2.215 & $.028 *$ & Full-time \\
\hline & & & Marital status & .132 & 1.961 & $.051 *$ & Married \\
\hline Counselling & $4.21(1.32)$ & $4.43(1.38)$ & - & - & - & - & \\
\hline Hypnotherapy & $3.23(1.59)$ & $3.19(1.64)$ & Culture & .131 & 2.083 & $.038^{*}$ & Non-Western \\
\hline Stress management & $4.20(1.27)$ & $4.35(1.34)$ & Therapy & .148 & 2.586 & $.010 * *$ & No previous \\
\hline \multirow[t]{2}{*}{ Support group } & $3.57(1.60)$ & $3.18(1.67)$ & Sex & -.163 & -2.781 & $.006 * *$ & Men \\
\hline & & & Education & -.119 & -1.986 & $.048 *$ & Lower education \\
\hline EMDR & $3.16(1.46)$ & $3.14(1.53)$ & - & - & - & - & \\
\hline
\end{tabular}




\section{Other preferences for therapy}

Table 3 shows how much men and women liked various aspects of therapy, and how much they like a therapy based on their previous experience of therapy. Table 3 shows that the most frequent predictors of other preferences for therapy were Age and Marital status (each three of 14 variables, or $21 \%$ ).

Regarding the preferences for the sex of the therapist (not shown in Table 3, because the outcome variable had three levels instead of two), most men and women ( $62 \%$ of men, $n=67 ; 61 \%$ of women, $n=133$ ) did not mind whether the therapist was male or female. $22 \%$ of men and $34 \%$ of women preferred a female therapist, and $17 \%$ of men and $5 \%$ of women preferred a male therapist. The differences are statistically significant $\left(\chi^{2}=15.498, \mathrm{df}=2, p<.0005\right)$. 
Table 3. Mean (SD) sex difference in likability rating for various aspects of therapies. For each variable the $\beta$ and $t$ values show the effect of gender in multiple linear regression, using the enter method, controlling for the effect of Sex, Age, Ethnicity, from a

Westernised country, Educational status, Occupational status, Marital status, Income, Relied on by others, and Whether have had therapy before. The $\beta$ and $t$ values for other variables are shown only where significant.

\begin{tabular}{|c|c|c|c|c|c|c|c|}
\hline Criterion variable & $\begin{array}{c}\text { Men } \\
(\mathrm{N}=111)\end{array}$ & $\begin{array}{l}\text { Women } \\
(\mathrm{N}=217)\end{array}$ & Predictor & $\boldsymbol{\beta}$ & $t$ & $\boldsymbol{P}$ & Liked most by... \\
\hline Individual therapy in a clinic & $5.14(1.05)$ & $5.31(1.10)$ & - & - & - & - & \\
\hline \multirow[t]{3}{*}{ Couples or family therapy in a clinic } & $3.47(1.35)$ & $3.38(1.57)$ & Ethnicity & .162 & 2.595 & .010 & Non-White \\
\hline & & & Age & -.152 & -2.349 & .019 & Young \\
\hline & & & Marital status & .282 & 4.275 & .0001 & Married \\
\hline Individual therapy at home & $3.56(1.50)$ & $3.60(1.69)$ & Education & -.135 & -2.245 & .025 & Less edu. \\
\hline Couples or family therapy at home & $3.00(1.48)$ & $3.00(1.58)$ & Marital status & .142 & 2.094 & .037 & Married \\
\hline Individual therapy in a neutral place & $3.76(1.47)$ & $3.63(1.50)$ & - & - & - & - & - \\
\hline Couples or family therapy in a neutral place & $3.07(1.46)$ & $2.76(1.42)$ & Marital status & .133 & 1.949 & .052 & Married \\
\hline Not therapy, but meet with others for social support & $3.90(1.37)$ & $3.62(1.58)$ & Age & -.209 & -3.148 & .002 & Young \\
\hline Telephone helpline & $2.74(1.42)$ & $2.97(1.56)$ & - & - & - & ns & \\
\hline Online therapy e.g. Skype or instant chat & $2.86(1.40)$ & $2.78(1.50)$ & Income & .154 & 2.309 & .022 & Wealthy \\
\hline Educational workshop e.g. Stress Management & $3.85(1.20)$ & $3.75(1.48)$ & - & - & - & ns & \\
\hline Prerecorded therapy via a CD, video or podcast & $2.75(1.49)$ & $2.72(1.51)$ & - & - & - & ns & \\
\hline Self-help books & $3.38(1.40)$ & $3.49(1.50)$ & - & - & - & ns & \\
\hline \multirow[t]{3}{*}{ Self-help websites } & $3.39(1.31)$ & $3.45(1.46)$ & Income & .193 & 2.953 & .003 & Wealthy \\
\hline & & & Relied on & .112 & 1.962 & .051 & Less relied on \\
\hline & & & Age & -.129 & -1.962 & .051 & Young \\
\hline Group psychological therapy & $3.20(1.37)$ & $2.82(1.54)$ & Sex & -.139 & -2.331 & .020 & Men \\
\hline
\end{tabular}

Table 4 shows that the two most frequent predictors of coping strategies were Age (eight of 23 variables, or $35 \%$ ) and Sex (seven of 23 variables, or $30 \%$ ). 
Table 4. Differences in male and female respondents for coping strategies. For each variable the $\beta$ and $t$ values show the effect of gender in logistic regression, using the enter method, controlling for the effect of Sex, Age, Ethnicity, from a Westernised country, Educational status,

Occupational status, Marital status, Income, Relied on by others, and Whether have had therapy before. The $\beta$ and $t$ values for other variables are shown only where significant.

\begin{tabular}{|c|c|c|c|c|c|c|c|c|c|}
\hline \multicolumn{2}{|l|}{ Criterion variable } & \multirow{2}{*}{$\begin{array}{c}\begin{array}{c}\text { Men } \\
(\mathrm{N}=108)\end{array} \\
80(74 \%)\end{array}$} & \multirow{2}{*}{$\begin{array}{c}\begin{array}{c}\text { Women } \\
(\mathrm{N}=211)\end{array} \\
177(84 \%)\end{array}$} & \multirow{2}{*}{$\begin{array}{c}\text { Predictor } \\
\text { Sex }\end{array}$} & \multirow{2}{*}{$\begin{aligned} \text { Sig } \\
.013\end{aligned}$} & \multirow{2}{*}{$\begin{array}{r}\operatorname{Exp}(\mathbf{B}) \\
2.255\end{array}$} & \multicolumn{2}{|c|}{ CI (95\%) } & \multirow{2}{*}{$\begin{array}{c}\begin{array}{c}\text { Used most } \\
\text { by.... }\end{array} \\
\text { Female }\end{array}$} \\
\hline Talking with friends & Yes & & & & & & 1.189 & 4.274 & \\
\hline & & & & Age & .030 & .973 & .949 & .997 & Young \\
\hline & & & & Education & .005 & 1.266 & 1.073 & 1.494 & Higher edu. \\
\hline Talking with family & Yes & $53(49 \%)$ & $126(60 \%)$ & Age & .014 & .975 & .955 & .995 & Young \\
\hline Talking to spiritual advisor & Yes & $17(16 \%)$ & $26(12 \%)$ & Western culture & .020 & 3.477 & 1.221 & 9.897 & Non-Western \\
\hline \multirow[t]{3}{*}{ Pray } & Yes & $23(21 \%)$ & $47(22 \%)$ & Ethnicity & .006 & 2.663 & 1.334 & 5.319 & Non-white \\
\hline & & & & Western culture & .049 & 2.388 & 1.003 & 5.687 & Non-Western \\
\hline & & & & Divorced/widowed & .031 & .096 & .011 & .802 & Married \\
\hline \multirow[t]{2}{*}{ Meditate } & Yes & $43(40 \%)$ & $68(32 \%)$ & Education & .016 & 1.193 & 1.034 & 1.377 & Higher edu. \\
\hline & & & & Therapy & .031 & .578 & .351 & .951 & Had therapy \\
\hline \multirow[t]{2}{*}{ Self-help book } & Yes & $34(32 \%)$ & $84(40 \%)$ & Sex & .045 & 1.723 & 1.013 & 2.932 & Female \\
\hline & & & & Education & .010 & 1.196 & 1.043 & 1.370 & Higher edu. \\
\hline \multirow[t]{2}{*}{ Take prescription medication } & Yes & $29(27 \%)$ & $110(52 \%)$ & Sex & .0001 & 3.032 & 1.757 & 5.230 & Female \\
\hline & & & & Therapy & .00005 & .351 & .214 & .574 & Had therapy \\
\hline Take OTC or herbal meds & Yes & $14(13 \%)$ & $49(23 \%)$ & Occupation & .010 & .407 & .205 & .806 & Unemployed \\
\hline Drink alcohol & Yes & $27(25 \%)$ & $54(26 \%)$ & Western culture & .030 & .103 & .013 & .800 & Western \\
\hline Take drugs & Yes & $10(9 \%)$ & $14(7 \%)$ & Therapy & .009 & .248 & .087 & .705 & Had therapy \\
\hline \multirow[t]{2}{*}{ Comfort eating } & Yes & $33(31 \%)$ & $108(51 \%)$ & Sex & .001 & 2.427 & 1.440 & 4.089 & Female \\
\hline & & & & Therapy & .018 & .566 & .353 & .907 & Had therapy \\
\hline Fasting & Yes & $7(7 \%)$ & $17(8 \%)$ & Therapy & .014 & .287 & .106 & .778 & Had therapy \\
\hline \multirow{2}{*}{ Have sex or use pornography } & Yes & $29(27 \%)$ & $23(11 \%)$ & Sex & .0002 & .280 & .144 & .545 & Male \\
\hline & & & & Age & .050 & .967 & .936 & 1.000 & Young \\
\hline \multirow[t]{2}{*}{ Exercise } & Yes & $61(57 \%)$ & $117(56 \%)$ & Age & .019 & .975 & .955 & .996 & Young \\
\hline & & & & Education & .001 & 1.247 & 1.091 & 1.424 & Higher edu. \\
\hline Take a holiday & Yes & $41(38 \%)$ & $96(46 \%)$ & - & - & - & - & - & \\
\hline Spend more time at work or studies & Yes & $32(30 \%)$ & $55(26 \%)$ & Being single & .032 & 2.034 & 1.063 & 3.893 & Single \\
\hline Spend more time with family & & $30(28 \%)$ & $71(34 \%)$ & Relied on & .028 & .777 & .621 & .973 & Not relied on \\
\hline Spend more time with friends & & $38(35 \%)$ & $90(43 \%)$ & Age & .044 & .978 & .957 & .999 & Young \\
\hline Take up a hobby & & $37(34 \%)$ & $82(39 \%)$ & - & - & - & - & - & - \\
\hline Do arts or crafts & & $18(17 \%)$ & $64(30 \%)$ & Sex & .001 & 2.785 & 1.481 & 5.239 & Female \\
\hline
\end{tabular}




\begin{tabular}{|c|c|c|c|c|c|c|c|c|}
\hline \multirow{3}{*}{ Play video / Internet games } & \multirow{3}{*}{$31(29 \%)$} & \multirow{3}{*}{$37(18 \%)$} & \multirow{3}{*}{$\begin{array}{c}\text { Education } \\
\text { Sex } \\
\text { Age }\end{array}$} & .010 & 1.229 & 1.052 & 1.436 & \multirow{3}{*}{$\begin{array}{c}\text { Higher edu. } \\
\text { Male } \\
\text { Young }\end{array}$} \\
\hline & & & & .007 & .435 & .238 & .794 & \\
\hline & & & & .017 & .968 & .943 & .994 & \\
\hline \multirow[t]{2}{*}{ Chat to people on Internet } & $20(19 \%)$ & $39(19 \%)$ & Age & .005 & .958 & .930 & .987 & Young \\
\hline & $38(35 \%)$ & $74(35 \%)$ & $\begin{array}{c}\text { Therapy } \\
\text { Age }\end{array}$ & $\begin{array}{l}.006 \\
.005\end{array}$ & $\begin{array}{l}.406 \\
.967\end{array}$ & $\begin{array}{l}.215 \\
.944\end{array}$ & $\begin{array}{l}.768 \\
.990\end{array}$ & $\begin{array}{c}\text { Had therapy } \\
\text { Young }\end{array}$ \\
\hline
\end{tabular}

\section{Sex difference in help-seeking}

Table 5 shows that the most frequent predictor of help-seeking behaviour was Sex (five of 18 variables, or $28 \%$ ). 
Table 5. Difference in male and female respondents for aspects of causes of help-seeking. Values are show as frequency (percentage). For each variable the $\beta$ and $t$ values show the effect of gender in logistic regression, using the enter method, controlling for the effect of Sex, Age, Ethnicity, from a Westernised country, Educational status, Occupational status, Marital status, Income,

Relied on by others, and Whether have had therapy before. The $\beta$ and $t$ values for other variables are shown only where significant.

\begin{tabular}{|c|c|c|c|c|c|c|c|c|c|}
\hline Criterion variable & & $\begin{array}{c}\text { Men } \\
(\mathrm{N}=108)\end{array}$ & $\begin{array}{l}\text { Women } \\
(\mathrm{N}=210)\end{array}$ & Predictor & Sig & $\operatorname{Exp}(B)$ & \multicolumn{2}{|c|}{ CI $(95 \%)$} & \multirow{2}{*}{$\begin{array}{c}\begin{array}{c}\text { Cited most } \\
\text { by... }\end{array} \\
\text { Full-time }\end{array}$} \\
\hline Impact on work & Yes & $15(13 \%)$ & $29(13 \%)$ & Occupation & .049 & .453 & .206 & .997 & \\
\hline Impact on relationships & Yes & $9(8 \%)$ & $25(11 \%)$ & & - & - & - & - & \\
\hline Impact on daily life & Yes & $11(10 \%)$ & $45(19 \%)$ & Sex & .008 & 2.749 & 1.309 & 5.776 & Female \\
\hline Need a nudge from another & Yes & $23(20 \%)$ & $42(18 \%)$ & Relied on & .046 & 1.262 & 1.005 & 1.584 & Less relied on \\
\hline \multirow[t]{2}{*}{ Self-aware } & Yes & $35(30 \%)$ & $96(41 \%)$ & Sex & .033 & 1.768 & 1.048 & 2.984 & Female \\
\hline & & & & Therapy & .004 & .496 & .308 & .801 & Previous \\
\hline \multirow[t]{2}{*}{ Seeks help at crisis point } & Yes & $12(10 \%)$ & $36(16 \%)$ & Marital status & .029 & 4.073 & 1.153 & 14.389 & Non-married \\
\hline & & & & Therapy & .011 & .307 & .149 & .633 & Previous \\
\hline \multirow[t]{2}{*}{ Fix problems myself } & Yes & $9(8 \%)$ & $2(1 \%)$ & Sex & .003 & .067 & .012 & .392 & Male \\
\hline & & & & Marital status & .032 & 8.430 & 1.195 & 59.466 & Single \\
\hline \multirow[t]{2}{*}{ Anonymity Preference } & Yes & $38(35 \%)$ & $80(39 \%)$ & Age & .051 & 1.022 & 1.000 & 1.044 & Young \\
\hline & & & & Occupation & .028 & .538 & .310 & .934 & Unemployed \\
\hline
\end{tabular}




\begin{tabular}{|c|c|c|c|c|c|c|c|c|c|}
\hline \multirow[t]{2}{*}{ Improve access } & Yes & $32(28 \%)$ & $77(33 \%)$ & Age & .037 & 1.022 & 1.001 & 1.044 & Older \\
\hline & & & & Therapy & .011 & .527 & .322 & .864 & Previous less \\
\hline \multirow[t]{2}{*}{ Make therapy affordable } & Yes & $7(6 \%)$ & $10(4 \%)$ & Ethnicity & .015 & 4.136 & 1.321 & 12.949 & Non-white \\
\hline & & & & Therapy & .028 & .257 & .076 & .864 & Previous less \\
\hline Ensure confidentiality & Yes & $2(2 \%)$ & $7(3 \%)$ & - & - & - & - & - & \\
\hline Remove cultural stigmas & Yes & $12(10 \%)$ & $28(12 \%)$ & Marital Status & .003 & 6.560 & 1.904 & 22.602 & Married less \\
\hline General education & Yes & $30(26 \%)$ & $54(23 \%)$ & - & - & - & - & & \\
\hline \multirow[t]{2}{*}{ Men don't admit to problems } & Yes & $38(33 \%)$ & $45(19 \%)$ & Sex & .011 & .491 & .283 & .852 & Male \\
\hline & & & & Ethnicity & .036 & .463 & .225 & .951 & White \\
\hline Embarrassment & Yes & $12(10 \%)$ & $26(11 \%)$ & - & - & - & - & - & \\
\hline Cultural Stigma & Yes & $36(31 \%)$ & $70(30 \%)$ & Age & .006 & .968 & .945 & .990 & Young \\
\hline \multirow[t]{2}{*}{ No male friendly options } & Yes & $18(16 \%)$ & $11(5 \%)$ & $\operatorname{Sex}$ & .002 & .264 & .112 & .624 & Male \\
\hline & & & & Education & .003 & 1.614 & 1.177 & 2.214 & Educated \\
\hline
\end{tabular}




\section{Significance of findings overall}

In Tables 2-5, a total of 62 variables were tested. Fifteen of the 62 tests (24\%) were statistically significant at the .05 level. To test whether this number was greater than would be expected by chance ( 1 in 20 , or $5 \%$ ), the binomial test was applied; this revealed that the proportion of statistically significant sex differences was significantly greater than chance (Exact $p<.0001$, one-tailed).

A familywise correction to the error rate for the number of domains tested (four: therapies, aspects of therapy, coping, help-seeking) raised the significance threshold to $p$ $<.0125(.05 / 4)$. Taking this as the significance level, the number of significant findings is reduced from 15 to 10 variables (from $24 \%$ to 16\%): support groups, taking medication, comfort eating, using sex or pornography, taking up arts or crafts, using video or Internet games, and four help-seeking variables (impact on daily life, fixing problems by self, not admitting to problems, no male-friendly options). Nonetheless, the binomial test revealed the proportion of statistically significant sex differences remained significantly greater than chance (Exact $p<.001$, one-tailed).

\section{Discussion}

This cross-sectional online survey assessed participants' self-report of preferences for types of therapy, general therapy preferences, coping strategies, and help-seeking behaviour. Although we found many similarities in the preferences of men and women, overall the findings support the hypothesis that men and women show significant differences in some areas, which may have implications for clinical practice. For the sake of brevity, this discussion will focus mainly on findings relating to sex differences rather than other findings.

Table 2 shows that the sex of the participant predicted $25 \%$ (two of eight) of the therapies listed. Women liked psychotherapy more than men did (although this difference was not significant after familywise correction) perhaps due to the emphasis on the sharing of emotion. Men liked support groups $(p<.006)$ significantly more than women did, perhaps due to the emphasis on the sharing of information. This echoes findings from IAPT that of the therapies on offer, women liked counselling the most, whereas men liked occupational support (Health and Social Care Information Centre, Community and Mental Health Team, 2014). It also supports the findings of Tamres et al. (2002) that for coping with stress, men focus less on sharing of emotions than women do. Studies have also found that men were more likely to indicate that they find talking to professionals, for example, psychologists difficult (Clement et al., 2015), which may be one reason why men do not seek professional mental health support as much as women do. While men may benefit as much as women from some form of emotional disclosure, they may be put off seeking help because of a reluctance to engage in interventions in which the importance of emotional disclosure is emphasized. 
Table 1 shows that most men (62\%) and most women (61\%) had no preference with regard to the gender of their therapist. This shows mixed support for the results of Pikus and Heavey (1996), who found that although most men did not show a preference $(58 \%)$, most women preferred a female therapist (56\%). It should be noted however that their study focused on psychotherapy alone, whereas the question about therapist preferences in the present study did not specify any particular therapy. In the present study, of those who did state a preference, women overwhelmingly preferred a female therapist (34\%) to a male therapist (5\%), whereas males only marginally preferred a female therapist (22\%) to a male therapist (17\%). It might be that in what could be perceived as an uncomfortable situation to begin with, people feel most comfortable with a person of their own sex (Pikus \& Heavey, 1996). This might be especially true when the presenting problem is related to male gender role expectations (Proctor, 2008), and where the therapist might provide a positive model of masculinity to the clients (Isacco, Hammer, \& Shen-Miller, 2016).

Are more male psychologists needed (Bullen \& Hacker Hughes, 2016)? The number of male doctoral psychology graduates in the United States has fallen from $80 \%$ in 1973 to $25 \%$ in 2009 (Isacco et al., 2016). There are currently 8,264 psychologists employed by the NHS in England, 19\% of whom are male. Males only make up 15\% of new clinical psychology trainees (Joubert, 2016), and 19\% of those studying psychology at undergraduate and A-level (Bullen \& Hacker Hughes, 2016). Little wonder there is a growing concern regarding this gender imbalance (Barrow, Gibbs, Lumsdon, Parker, \& Peters, 2016). If the majority of clients have no preference regarding the gender of their therapist, then an increase in the number of male psychologists will not have a negative effect on their expectations. It will, however, increase the likelihood of a male therapist being available where there is a preference for a male psychologist. Men are more vulnerable to suicide and less likely to seek help, so ensuring the availability of a male therapist might be important.

Table 4 shows that the sex of the participant predicted 30\% (seven of 23) of the coping strategies, and their age predicted $35 \%$ (eight of 23 ). Women were more likely than men to talk to friends $(p<.013)$, although this difference was not significant after familywise correction. This finding provides some support for the Taylor et al. (2000) hypothesis that women 'tend and befriend' when distressed, and echoes the finding that men are less likely than women to talk to someone when experiencing depression (CALM (The Campaign Against Living Miserably), 2016).

Women were more likely than men to comfort eat $(p<.001)$. Previous evidence suggests that stress affects men and women differently in relation to their eating habits and that emotional eating is more likely in women than in men (Oliver \& Wardle, 1999). This could be supported by evidence that women are more likely than men to ruminate when stressed (Tamres et al., 2002) and comfort eaters are likely to eat to avoid rumination (Gibson, 2012), which could be why comfort eating tends to be associated 
more so with women than men.

This present study shows that women were significantly more likely than men to want to use prescription medication $(p<.0005)$ as a way to cope with stress. This apparently contradicts psychological therapists who reported that men want a quick fix and women want to explore their (Holloway et al., in review) feelings. Previous research shows that more men than women engage in substance abuse (McManus, Bebbington, Jenkins, \& Brugha, 2016), so men might self-medicate in this way rather than with prescription medication. Interestingly, the present study found no sex difference in the use of alcohol or drugs. However, the present finding that men use medication less is because they go to their family doctor less (Wang, Hunt, Nazareth, Freemantle, \& Petersen, 2013) and are concerned about balancing the risk and benefits of medication (Scholz, Crabb, \& Wittert, 2016). It may also be related to stigma surrounding having mental health problems. For example, disproportionately fewer men are diagnosed with and treated for depression than women, possibly due to depression not being recognized as easily in men, and making it harder to diagnose (Branney \& White, 2008) because when men are depressed they might act out in different ways from women (Brownhill, Wilhelm, Barclay, \& Schmied, 2005; CALM (The Campaign Against Living Miserably), 2016).

This present study shows that men were significantly more likely than women to admit to having sex or using pornography $(p<.0002)$, as well as play video or Internet games $(p<.007)$ as a way to cope with stress. These findings are not surprising as men more than women engage in masturbation (Oliver \& Hyde, 1993) and video games (Stoet $\&$ Yang, 2016). These types of behaviours can be understood as distraction strategies, a method of coping which is generally more likely to be used by men (Tamres et al., 2002). Furthermore, both of these activities involve hormonal changes that may be implicated in mood state change. For example, watching Internet pornography was found to be more of a motivating factor for men than women as a way to maintain mood (Paul \& Shim, 2008). Although no gender distinction was highlighted, a study by Ferguson and Rueda (2010) found that playing violent video games provided some individuals with an ability to tolerate stress.

Table 4 showed that those who had had previous therapy preferred to take prescription medication $(p<.0005)$, drugs $(p<.009)$, or chat to people on the Internet $(p$ $<.006)$. These findings are not completely unexpected; the standard offerings from the NHS for treatment of depression tend to be some combination of psychological therapy and medication (NICE, 2016), so it is not surprising that those who have engaged in therapy may also already have taken prescribed medication. Indeed, prior experience of therapy may mean that people are more likely to accept they have a mental illness and are thus more likely to take medication for it. It should be noted, however, that it is not possible to know whether participants equated taking drugs with prescription medication or other legal or illegal drugs. 
Table 5 shows that the sex of the participant predicted $28 \%$ (five of 16 ) of the help-seeking themes identified. Women were more likely than men to rely on selfawareness of their mental health needs as a prompt to seek help $(p<.033)$, although this difference was not significant after familywise correction. This ties in with the suggestion that men are more prone to alexithymia (reduced ability to identify and articulate feelings; Levant et al., 2006), which would possibly explain previous findings that men are more likely than women to seek help if prompted by a family member (Lemkey et al., 2015; Norcross et al., 1996; Russ et al., 2015), although this was not explicitly stated in the present study. Women were more likely than men to say that an 'impact on their daily life' triggered them to seek help $(p<.008)$. Impact on work was not a significant predictor for either sex, which is in contrast to Russ et al. (2015), who found that, for men, help-seeking was associated with business rather than personal issues, with men being more likely to speak about personal issues only if such issues impacted their work.

Those who had previous therapy were more self-aware $(p<.004)$ and more likely to seek help at crisis point $(p<.011)$. Even though no gender difference was found, men are more at risk of completing suicide than women, suggesting that there may be preventative benefits for men engaging in some form of therapy. However, the degree to which the previous therapy experience was positive may act as a mediating factor, pointing to the importance of providing men with a range of options that are suited to their therapeutic needs. There was also a small number of participants - predominantly men $(p<.003)$ - who reported that they would not seek any help at all, in some cases inferring that they would just fix their problems themselves. This echoes the general consensus that men do not seek psychological help as much as women do (e.g., Addis \& Mahalik, 2003; Kung et al., 2003).

Men were more likely than women $(p<.011)$ to identify stereotypically male traits as barriers to seeking help. It was a fairly common theme that men find it harder to admit to having problems and do not express themselves in the same way as women do. Again, alexithymia might be implicated here. Unexpectedly, neither men nor women identified embarrassment as a significant barrier for men, contrary to the findings of CALM (The Campaign Against Living Miserably), 2016.

Stigma was commonly cited as a barrier to male help-seeking, and women as well as men indicated some awareness of the conflict between the societal expectation that men should be strong, and societal judgements that help-seeking is a sign of weakness. However, there was no significant difference related to in the impact of stigma on men compared to women, which does not support the finding of Clement et al. (2015) that stigma was more of a deterrent for men than women. Seager, Farrell, and Barry (2016) suggest that a way to overcome societal expectations of men could be to reframe helpseeking as something that a strong man does.

Men were more likely than women $(p<.002)$ to identify systemic barriers to helpseeking by men, reflecting the view that treatment options do not tend to be male 
friendly. Seager, Sullivan, and Barry (2014) refer to 'male gender blindness' when discussing how the male gender can be unintentionally ignored, which might explain how the specific needs of men are often not considered in therapy (Golden, 2013; Kingerlee et al., 2014). For example, men find talking to professionals such as psychologists difficult (Clement et al., 2015), which may be one reason why men do not seek formal help as much as women do. This could also explain why men in the present study liked support groups more than women did, their informal nature having more appeal, as seen in the popularity of Men's Sheds (Wilkins, 2010). Changes to services themselves and the ways in which they are delivered, both in the United Kingdom and internationally, are starting to make help-seeking more accessible for men, a trend likely to continue in the United Kingdom given the current trajectory (Kingerlee et al., 2014).

By focusing on gender differences in this paper, we have not highlighted preferences in absolute terms. For example, Table 2 shows that for both men and women CBT was their most-liked therapy. This may be because CBT is widely known of, or perhaps because it is a treatment that combines problem-solving as well as talking about feelings. Table 3 shows that the aspect of therapy most liked by both men and women was individual therapy in a clinic. Although Table 2 showed that men preferred group support significantly more than women did, this finding may be driven by women's relative dislike of group support compared to other therapies. Table 4 shows that the coping strategy most used by men and women was talking with friends. It may be that men and women have different ways of talking with friends; for example, men may chat about sports or other topics as well as talking about their feelings (Roper \& Barry, 2016). Table 5 shows that the most important factor in seeking help was as follows: for women: self-awareness of the problem, and for men: anonymity.

These findings of absolute preferences show that despite the gender differences highlighted in this paper, there are also important gender similarities.

\section{Clinical implications}

The findings of this study have implications for the training of clinical psychologists and other psychological therapists. Although not focusing specifically on gender preferences, a review has shown that honouring client therapy preferences improves treatment outcomes and reduces the likelihood of clients dropping out of therapy prematurely (Swift, Callahan, \& Vollmer, 2011). Men's awareness of their own issues around, and difficulties with, self-disclosure, for instance, have already started to inform how services are designed and delivered in the United Kingdom and elsewhere. The present study offers several new and potentially important avenues for exploration and intervention. For example, if younger people are significantly more likely to seek help or support via the Internet, and men are more inclined than women to use online and video games to deal with stress (Table 4), then mental health policy and practice should be adjusted 
accordingly to maximize effectiveness and value in reaching out to men and younger people.

\section{Strengths, limitations, and future directions}

This is the first exploration of sex differences with regard to the preferences of clients, and potential clients, in therapy. A wide range of questions were posed to a sample which included a balance of people with and without experience of therapy and mental health issues. The findings of this study are likely to have significant clinical benefits in helping design interventions, as well as attracting men to therapy, thus potentially reducing suicides.

To reduce the number of items in the survey, we combined some categories of behaviour, for example, watching pornography and engaging in sexual behaviours. This combination may obscure relevant differences in how pornography and sex are used as coping strategies. For example, it could be that some aspects are dysfunctional and others not. Future studies might investigate this and other areas further.

The present study offered descriptions of therapies (e.g., counselling) and asked participants to rate how much they liked each. Future studies may benefit from anonymizing the names of the therapies (e.g., Therapy A, Therapy B, etc.), to avoid any bias towards certain therapies due to familiarity or preconceptions.

\section{Conclusion}

This study has shown that men and women differ in important ways with regards to their preferences for therapy, coping styles, and help-seeking behaviours. Age, ethnicity, income, marital status, educational status, and occupational status, as well as previous experience of therapy, were also found to predict preferences. Because male help-seeking seems to be hampered by barriers at both the personal level (i.e., men struggle asking for help) and systematic level (i.e., lack of male-friendly services), more attention is needed to address the issue of improving uptake of mental health services by men. We hope our findings improve the way health services are presented and delivered to patients, particularly in offering men treatment options that they will be more inclined to use. 


\section{References}

Addis, M. E., \& Mahalik, J. R. (2003). Men, masculinity, and the contexts of help-seeking. American Psychologist, 58(1), 5-14. https://doi.org/10.1037/0003-066X.58.1.5

Barrow, W., Gibbs, S., Lumsdon, D., Parker, R., \& Peters, B. (2016). Does it matter if psychologists are unrepresentative? The Psychologist, 29. Retrieved from http://tinyurl.com/j1265bn

Barry, J. A., Folkard, A., \& Ayliffe, W. (2014). Validation of a brief questionnaire measuring positive mindset in patients with uveitis. Psychology, Community \& Health, 3(1), 1. https://doi.org/10. 5964/pch.v3i1.76

Branney, P., \& White, A. (2008). Big boys don't cry: Depression and men. Advances in Psychiatric Treatment, 14, 256-262. https://doi.org/10.1192/apt.bp.106.003467

Brook, L., Hedges, S., . Jowell, R., Lewis, J., Prior, G., Sebastian, G., Taylor, B., \& Witherspoon, S. (1992). British social attitudes cumulative sourcebook: First 6 surveys. Aldershot, UK: Gower.

Brownhill, S., Wilhelm, K., Barclay, L., \& Schmied, V. (2005). 'Big build': Hidden depression in men. Australian and New Zealand Journal of Psychiatry, 39(10), 921-931. https://doi.org/10. 1111/j.1440-1614.2005.01665.x

Bullen, K., \& Hacker Hughes, J. (2016). Achieving representation in psychology: A BPS response. The Psychologist, 29. Retrieved from http://thepsychologist.bps.org.uk/volume29/april/repre sentativeness-psychologists-bps-response

CALM (The Campaign Against Living Miserably) (2016). Building Modern Men. Retrieved from http://tinyurl.com/j732ojd

Clement, S., Schauman, O., Graham, T., Maggioni, F., Evans-Lacko, S., Bezborodovs, N., ... Thornicroft, G. (2015). What is the impact of mental health-related stigma on help-seeking? A systematic review of quantitative and qualitative studies. Psychological Medicine, 45(01), 1127. https://doi.org/10.1017/S0033291714000129

Ferguson, C. J., \& Rueda, S. M. (2010). The hitman study. European Psychologist, 15(2), 99108. https://doi.org/10.1027/1016-9040/a000010

Gibson, E. L. (2012). The psychobiology of comfort eating: Implications for neuropharmacological interventions. Behavioral Pharmacology, 23(5 and 6), 442-460. https://doi.org/10.1097/fbp. 0b013e328357bd4e

Golden, T. (2013). The way men heal. Gaithersburg, MA: G.H. Publishing.

Green, J. P., Lynn, S. J., \& Montgomery, G. H. (2008). Gender-related differences in hypnosisbased treatments for smoking: A follow-up meta-analysis. American Journal of Clinical Hypnosis, 50(3), 259-271. https://doi.org/10.1080/00029157.2008.10401628 
Health and Social Care Information Centre, Community and Mental Health Team (2014). Data source: Improving Access to Psychological Therapies (IAPT) dataset. Retrieved from http:// www.hscic.gov.uk/article/2021/

Hochberg, Y., \& Tamhane, A. C. (1987). Multiple comparison procedures. New York, NY: Wiley.

Holloway, K., Seager, M., \& Barry, J. A. (in review). Are clinical psychologists and psychotherapists overlooking the gender-related needs of their clients?

Isacco, A., Hammer, J. H., \& Shen-Miller, D. S. (2016). Outnumbered, but meaningful: The experience of male doctoral students in professional psychology training programs. Training and Education in Professional Psychology, 10(1), 45. https://doi.org/10.1037/tep0000107

Joubert, H. E. (2016). Selection of Male Trainees. Presentation at University of Surrey. Retrieved from http://tinyurl.com/zve72hu

Kingerlee, R., Precious, D., Sullivan, L., \& Barry, J. A. (2014). Engaging with the emotional lives of men: Designing and promoting male-specific services and interventions. The Psychologist, 24, 418-421.

Kung, H. C., Pearson, J. L., \& Liu, X. (2003). Risk factors for male and female suicide decedents ages 15-64 in the United States. Social Psychiatry and Psychiatric Epidemiology, 38(8), 419426. https://doi.org/10.1007/s00127-003-0656-x

Lemkey, L., Brown, B., \& Barry, J. A. (2015). Gender distinctions: Should we be more sensitive to the different therapeutic needs of men and women in clinical hypnosis? Findings from a pilot interview study. Australian Journal of Clinical Hypnotherapy \& Hypnosis, 37(2), 10.

Levant, R. F., Good, G. E., Cook, S. W., O’Neil, J. M., Smalley, K. B., Owen, K., \& Richmond, K. (2006). The normative Male Alexithymia Scale: Measurement of a gender-linked syndrome. Psychology of Men \& Masculinity, 7(4), 212. https://doi.org/10.1037/1524-9220.7.4.212

McManus, S., Bebbington, P., Jenkins, R., \& Brugha, T. (eds.) (2016) Mental health and wellbeing in England: Adult Psychiatric Morbidity Survey 2014. Leeds, UK: NHS Digital.

NICE (2016). Retrieved from https://www.nice.org.uk/guidance/cg90/chapter/1-Guidance-careof-all-people-with-depression

Norcross, W. A., Ramirez, C., \& Palinkas, L. A. (1996). The influence of women on the health care- seeking behavior of men. Journal of Family Practice, 43(5), 475-481.

Oliver, M. B., \& Hyde, J. S. (1993). Gender differences in sexuality: A meta-analysis.

Psychological Bulletin, 114, 29-51. https://doi.org/10.1037/0033-2909.114.1.29

Oliver, G., \& Wardle, J. (1999). Perceived effects of stress on food choice. Physiology \& Behavior, 66(3), 511-515. https://doi.org/10.1016/S0031-9384(98)00322-9 
ONS, Office of National Statistics (2015). Suicide rates in the United Kingdom, 2013

Registrations. Retrieved from http://tinyurl.com/mzplbzr

Opinium Research (2016). Global study. men's health perceptions from around the globe. Retrieved from http://tinyurl.com/zspmeeu

Parker, G., Blanch, B., \& Crawford, J. (2011). Does gender influence response to different psychotherapies in those with unipolar depression? Journal of Affective Disorders, 130, 17-20. https://doi.org/10.1016/j.jad.2010.05.020

Paul, B., \& Shim, J. W. (2008). Gender, sexual affect, and motivations for Internet porno- graphy use. International Journal of Sexual Health, 20(3), 187-199. https://doi.org/10. 1080/19317610802240154

Peduzzi, P., Concato, J., Kemper, E., Holford, T. R., \& Feinstein, A. R. (1996). A simulation study of the number of events per variable in logistic regression analysis. Journal of Clinical Epidemiology, 49(12), 1373-1379. https://doi.org/10.1016/S0895-4356(96)00236-3

Peterson, B., Boivin, J., Norr_e, J., Smith, C., Thorn, P., \& Wischmann, T. (2012). An introduction to infertility counseling: A guide for mental health and medical professionals. Journal of Assisted Reproduction and Genetics, 29(3), 243-248. https://doi.org/10.1007/s10815$011-9701-y$

Pikus, C. F., \& Heavey, C. L. (1996). Client preferences for therapist gender. Journal of College Student Psychotherapy, 10(4), 35-43. https://doi.org/10.1300/J035v10n04_05

Proctor, G. (2008). Gender Dynamics in Person-Centered Therapy: Does gender matter. PersonCentered \& Experiential Psychotherapies, 7(2), 82-94. https://doi.org/10.1080/14779757. 2008.9688455

Roper, T., \& Barry, J. A. (2016). Is having a haircut good for your mental health? New Male Studies, 5(2), 58-74.

Russ, S., Ellam-Dyson, V., Seager, M., \& Barry, J. A. (2015). Coaches' views on differences in treatment style for male and female clients. New Male Studies, 4(3), 75-92.

Scholz, B., Crabb, S., \& Wittert, G. A. (2016). "Males don't wanna bring anything up to their doctor" men's discourses of depression. Qualitative Health Research, 27(5), 727-737. https://doi.org/ 1049732316640294

Seager, M. J., Farrell, W., \& Barry, J. A. (2016). The male gender empathy gap: Time for psychology to take action. New Male Studies, 5(2), 6-16.

Seager, M., Sullivan, L., \& Barry, J. A. (2014). The male psychology conference, university college London, June 2014. New Male Studies, 3, 41-68.

Stoet, S., \& Yang, J. (2016). The boy problem in education and a 10-point proposal to do something about it. New Male Studies, 5, 17-35. 
Swift, J. K., Callahan, J. L., \& Vollmer, B. M. (2011). Preferences. Journal of Clinical Psychology, 67(2), 155-165. https://doi.org/10.1002/jclp.20759

Tabachnick, B. G., \& Fidell, L. S. (2001). Using multivariate statistics. Boston, MA: Allyn and Bacon.

Tamres, L. K., Janicki, D., \& Helgeson, V. S. (2002). Sex differences in coping behavior: A meta- analytic review and an examination of relative coping. Personality and Social Psychology Review, 6(1), 2-30. https://doi.org/10.1207/S15327957PSPR0601_1

Taylor, S. E., Klein, L. C., Lewis, B. P., Gruenewald, T. L., Gurung, R. A., \& Updegraff, J. A. (2000). Biobehavioral responses to stress in females: Tend-and-befriend, not fight-or-flight. Psychological Review, 107(3), 411. https://doi.org/10.1037/0033-295X.107.3.411

Wang, Y., Hunt, K., Nazareth, I., Freemantle, N., \& Petersen, I. (2013). Do men consult less than women? An analysis of routinely collected UK general practice data. British Medical Journal Open, 3(8), e003320. https://doi.org/10.1136/bmjopen-2013-003320

Wilkins, D. (2010). Untold problems. A review of the essential issues in the mental health of men and boys. Men's Health Forum. Retrieved from https://www.menshealthforum.org.uk/sites/defa ult/files/pdf/untold_problems.pdf

Wright, K., \& McLeod, J. (2016). Gender difference in changes in coping strategies: The effectiveness of brief therapy provided through an Employee Assistance Programme (EAP) in the U.K. New Male Studies, 5, 88-110. 